\title{
O Projeto Crítico em Schelling, Tillich e Goodchild
}

\author{
Daniel Whistler*
}

Compreender Kant significa transcender Kant

(Tillich, 1967, p. 70)

\begin{abstract}
RESUMO
$\mathrm{O}$ artigo procura estabelecer as condições e os elementos de uma teoria genuinamente crítica no estudo da religião: a partir de onde se crítica? Isso é, qual é o discurso ideal a partir do qual se pode embarcar no projeto crítico? Qual é o gênero da crítica? ${ }^{1}$ Se a crítica é inerentemente teológica, mas estruturada filosoficamente, são aqueles que criticam fi-

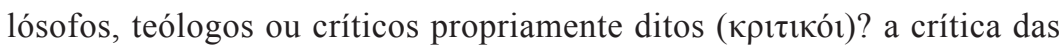
religiões e a reorientação da preocupação última é um ethos, uma ética do pensamento. $\mathrm{O}$ autor delinea esse ethos através de três manifestações de uma tradição distinta, ainda que subexplorada, de teologia radical, que atravessa Schelling, Tillich e Goodchild. O que os três têm em comum é o compromisso de atender àquilo que mais importa (piedade ou preocupação última) e a um projeto de crítica que radicalize a definição kantiana de transcendental a fim de chegar àquilo que escapa ao pensamento de Kant - os valores incondicionais ou "teológicos mais profundos" que orientam a existência pessoal.
\end{abstract}

Palavras-chave: Crítica, piedade, preocupação última, Schelling, Tillich, Goodchild

* Departamento de Filosofia, Royal Holloway, Universidade de Londres. Tradução: Carlos Eduardo Calvani (original: The Critical Project in Schelling, Tillich and Goodchild, in MANNING, R. R. (ed.). Retrieving the Radical Tillich: His Legacy and Contemporary Importance. New York: Palgrave Macmillan, 2015. p. 209-231.)

1 A obra de Lacoue-Labarthe e Jean-Luc Nancy a partir do final dos anos 70 também é impulsionada por essa pergunta (p. ex., LACOUE-LABARTHE e NANCY, The Literary Absolute: The Theory of Literature in German Romanticism, trans. Philip Bernard and Cheryl Lester. Albany: SUNY Press, 1988. 


\title{
The Critical Project in Schelling, Tillich and Goodchild
}

\begin{abstract}
The article seeks to establish the conditions and elements of a genuinely critical theory in the study of religion: from where is it criticized? That is, what is the ideal discourse from which one can embark on the critical project? What is the genre of criticism? If criticism is inherently theological, but philosophically structured, are those who criticize phi-

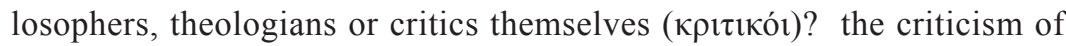
religions and the reorientation of the ultimate concern is an ethos, an ethics of thought. The author outlines this ethos through three manifestations of a distinct, if underexplored, tradition of radical theology, which runs through Schelling, Tillich and Goodchild. What the three have in common is the commitment to meet what matters most (piety or ultimate concern) and a project of criticism that radicalizes the Kantian definition of transcendental in order to reach what escapes Kant's thought - the unconditional or "theological" values that guide personal existence.
\end{abstract}

Keywords: Criticism, piety, ultimate concern, Schelling, Tillich, Goodchild

\section{Introdução - O gênero da preocupação última}

Uma teologia genuinamente radical é um pensamento teológico que realmente repensa o fundamento mais profundo da teologia, um repensar que é inicialmente um impensado de todo fundamento teológico estabelecido; somente através de tal impensado pode ser estabelecida uma clarificação para o pensamento teológico, e essa clareira é o primeiro objetivo da teologia radical. Porém, isso não pode ser conseguido com uma simples dissolução de nossas bases teológicas, pois essas são as mesmas que devem ser aqui desafiadas em última análise, e desafiadas em termos de suas reivindicações mais intrínsecas. (ALTIZER, 2012, p.1)

Assim começa o mais recente "apelo à teologia radical" de Altizer - e é sob o signo dessa tarefa de "não pensar" que desejo posicionar Tillich e uma tradição da teoria crítica. Esse é um chamado que ecoou nas obras de Tillich como um imperativo: "o conteúdo concreto da fé comum deve ser sujeito a críticas e transformação” (TILLICH, 1952, p. 172-173). 
Altizer e Tillich repetem um tropo cartesiano que está no cerne da modernidade: o começo deve ser destrutivo; abrir um espaço livre das ortodoxias, suposições e doxas que entopem as vias aéreas do pensamento. Chegar ao "ponto mais profundo da teologia" - que segundo Tillich, pode ser chamado "preocupação última", ou segundo Goodchild, "piedade" - ou seja, é preciso reorientar-se e reorientar a própria atenção. Essa reorientação é uma empresa crítica necessariamente destrutiva. Em outras palavras, a crítica genuína é a única maneira de chegar ao terreno da teologia (ou não-fundamento), para atingir o que mais importa. Além disso, quando Altizer transpõe teologicamente o slogan filosófico de que "é necessário que pelo menos uma vez na vida você duvide, na medida do possível, de todas as coisas" (DESCARTES, 1998, p. 112), ele problematiza a própria relação entre teologia e filosofia, desafiando a possibilidade de qualquer determinação ou relação hierárquica entre elas. Esse é um movimento recorrente em sua obra. No entanto, nesta conjuntura - nas próprias palavras de abertura de The Call to Radical Theology - emerge uma questão específica com a qual todos os pensadores discutidos neste artigo se vêem confrontados: a partir de onde se crítica? Isso é, qual é o discurso ideal a partir do qual se pode embarcar no projeto crítico? Qual é o gênero da crítica? ${ }^{2}$ Se a crítica é inerentemente teológica, mas estruturada filosoficamente,

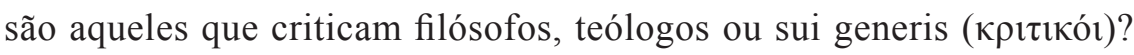

Essas são perguntas recentemente discutidas por um dos herdeiros de Altizer, Bradley Johnson, em uma análise da citação acima. Em The Theisticistic Theology of Herman Melville, Johnson afirma explicitamente que a reorientação do pensamento aos seus fundamentos - o que Altizer chama de "impensado teológico" e o próprio Johnson chama de "o pensamento da auto-criação da teologia como teologia" - necessariamente ocorre como "irônica dissolução de gênero" "(JOHNSON, 2012 , p. 77). Ele prossegue de um modo que nos lembra a metáfora

2 A obra de Lacoue-Labarthe e Jean-Luc Nancy a partir do final dos anos 70 também é impulsionado por essa pergunta (p. ex., LACOUE-LABARTHE e NANCY, The Literary Absolute: The Theory of Literature in German Romanticism, trans. Philip Bernard and Cheryl Lester. Albany: SUNY Press, 1988. 
da 'fronteira' de Tillich configurada como o 'centro' do pensamento 'frutífero's :

Minha concepção de teologia [é] um discurso ontológico fundamental que funciona melhor quando surge nos espaços entre qualquer número de discursos e disciplinas (...) O modelo interdisciplinar que espero exemplificar é investido naquilo que não é pensado no pensamento - ou seja, no que é radicalmente perturbado como excesso estético-teológico reprimido. Somente dessa maneira o pensamento de alguém sobre teologia se torna um pensamento teológico (TILLICH, 1987, p, 279).

Em outras palavras, a teologia não é um campo de discurso fechado, mas um excesso (produzido no próprio ato de fundamentar e não fundamentar) que circula pelo discurso. Portanto, o único critério para

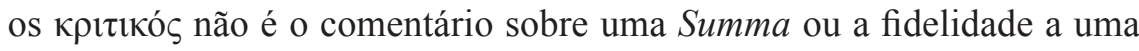
igreja, mas encontrar um lugar para se posicionar, que mais efetivamente aproveite esse excesso (onde quer que seja) ${ }^{4}$. Também devemos perguntar por que a teologia tem sido tradicionalmente restritiva a esse respeito; o que há no campo estabelecido da 'teologia' que precisa ser substituído? Novamente Johnson fornece orientação:

A teologia tradicional (...) começa e termina com a nomeação de sua preocupação última. Desse modo, diz muito e pouco (...). Há, é claro, uma diferença crucial entre um teólogo, aquele que nomeia e um filósofo, cuja atenção dirige-se às condições de se nomear. De fato (...) talvez apenas este último, o não-teólogo, possa estar verdadeiramente sintonizado com a promessa que atravessa as divisões religiosas, a de uma 'nova criação' (ou 'iluminação') - a criação de uma nova existência. (JOHNSON, 2010, p. 377-378).

O teólogo nomeia sem prestar atenção ao porquê, como ou com que direito ela o nomeia; conseqüentemente, o teólogo não está suficientemente atento para poder reorientar a piedade do pensamento (suas preocupações finais ou fundamentos mais profundos). $\mathrm{O}$ que não quer

3 Ver Paul Tillich, 'Philosophy and Theology' in Hauptwerke, ed. John Clayton et al (Berlin: De Gruyter, 1987), 4:279; Paul Tillich, 'On the Boundary’, trans. J. Heywood Thomas, in The Boundaries of Our Being (London: Fontana, 1973), 297.

4 Significativamente para este artigo, é que Johnson emprega, em sua argumentação, um modelo derivado de Weltalter, de Schelling. 
dizer que Johnson rejeite a teologia; em vez disso, ele continua falando de 'um novo pensamento teológico ... preocupado com o porquê e como ocorre a nomeação dos incondicionados' e, portanto, pratica 'uma ética ativa do pensamento incorporada pela atenção prestada àquilo que é impensável no pensável ${ }^{5}$. Este é um discurso que se identifica como teológico sem se aprisionar na cadeia de questões e preocupações teológicas tradicionais. Preocupa-se não apenas com nomes, mas com as condições de possibilidade de nomeação (é, portanto, crítico, no sentido estritamente kantiano); além disso, também excede o meramente filosófico, na medida em que se preocupa com o terreno do discurso que é excessivo ('expressando assim a experiência do abismo nos conceitos filosóficos' (TILLICH, 1973, p. 321). Nessa linha de pensamento, a crítica das religiões e a reorientação da preocupação última (ou seja, a teologia radical conforme definida por Altizer acima) é um ethos, uma ética do pensamento.

A seguir, traço esse ethos através de três manifestações de uma tradição distinta, ainda que subexplorada, de teologia radical, que atravessa Schelling, Tillich e Goodchild. O que os três têm em comum é o compromisso de atender àquilo que mais importa (piedade ou preocupação última) e a um projeto de crítica que radicalize a definição kantiana de transcendental ('todo conhecimento que não é ocupado tanto com objetos' quanto com o modo de nosso conhecimento dos objetos (KANT, 1929), a fim de chegar àquilo que escapa ao pensamento de Kant - os valores incondicionais ou "teológicos mais profundos" que orientam a existência pessoal. Durante todo o processo, tento não apenas falar os nomes dados para essas piedades, mas também descrever as condições que, para Schelling, Tillich e Goodchild, tornam possível esse processo de nomeação. O que está em aposta, portanto, é uma teoria genuinamente crítica.

\section{A Tradição neo-schellingiana}

A fim de justificar minha localização de Tillich em uma tradição que remonta a Schelling e encaminha a Goodchild, forneço algumas informações históricas. Esse contexto serve como um meio de trazer à

Ibid. Johnson aqui está citando Goodchild (como veremos a frente). 
tona o essencial do schellingianismo de Tillich, justificando provisoriamente seu lugar no cânone da teoria crítica, isto é, o desenvolvimento de um ethos de pensamento que é antes de tudo uma questão de crítica (no sentido kantiano). Foi quando estudante que Tillich descobriu os escritos de Schelling:

Lembro-me do momento inesquecível em que, por acaso, comprei um exemplar da raríssima primeira edição das obras completas de Schelling em um sebo no caminho da Universidade de Berlim. Eu não tinha muito dinheiro, mas comprei o livro mesmo assim. Esse gasto do dinheiro que eu não tinha foi, talvez, o mais importante de minha vida. O que aprendi de Schelling determinou minha linha de pensamento filosófico e teológico (TILLICH, 1986, p. 142),

De fato, em 26 de setembro de 1954, centenário da morte de Schelling e mais de quarenta anos após essa aquisição, Tillich falou novamente sobre o que Schelling significara para ele:

Senti que poderia expressar com esse discurso algo da admiração que devo ao meu grande mestre de filosofia e teologia. Ele foi meu mestre, embora entre o ano de sua morte e o início dos meus estudos tenham se passado exatamente cinquenta e anos; nunca no desenvolvimento do meu próprio pensamento, esqueci minha dependência de Schelling. Em todos os períodos, assim como no solo de uma cultura meio alheia, suas ideias fundamentais me ajudaram em todas as áreas (TILLICH, 1967, p. 392).

Conforme Tillich, então, o pensamento de Schelling permeia todo o seu pensamento ${ }^{6}$ - mas, é claro, não apenas o dele. Nossa compreensão da história das ideias na Europa do início do século XX é empobrecida se ela não incluir a categoria de "neo-schellingianismo" para descrever muitas das preocupações de Berdiaev, Bloch, Bulgakov, Frank, Heidegger, Jaspers, Marcel, Rosenzweig, assim como Tillich. Cada pensador (e é imediatamente perceptível que, de acordo com a linha de pensamento seguida na seção anterior, eles não podem ser facilmente descritos como filósofos ou teólogos) voltou ao trabalho de F.W.J. Schelling em busca de inspiração. Longe da visão dominante de Schelling como uma relí-

6 Isso implica a mitologização posterior de Tillich de seu encontro com Schelling; para uma tentativa concertada de desmitologizar isso, ver os trabalhos de Christian Danz, especialmente Religion als Freiheitsbewußtsein (Berlin: De Gruyter, 2000). 
quia pré-hegeliana, surgiu um Schelling que - para citar Jaspers (1955, p.332) - é "um protótipo de possibilidades modernas".

Em 1957, por exemplo, Gabriel Marcel no texto: Schelling fut-il un precurseur de la philosophie de l'existence? decidiu revisar esse retorno obsessivo a Schelling repetido nos últimos cinquenta anos. Ele escreve,

Se, para uma forma de pensamento que visa o rigor antes de mais nada, Schelling não pode ser um mestre ou um exemplo por considera, ao contrário disso, a filosofia como uma aventura heroica que envolve riscos e contorna abismos, ele sempre será um companheiro emocionante e, talvez até mesmo, uma inspiração. (MARCEL, 1957, p. 87).

Devemos lembrar que Marcel e outros neo-schellingianos escreveram em um vácuo acadêmico. Quando Tillich escreveu sua primeira tese de doutorado sobre Schelling, em 1910, não havia um estudo completo da filosofia posterior de Schelling, na qual ele mesmo pudesse se basear. Schelling ainda não havia sido domesticado pela universidade; em vez disso, como a citação acima claramente implica, o Schelling selvagem do início do século XX estava ao lado de Dostoiévski, Kierkegaard e Nietzsche como uma nova voz para os não-ortodoxos. Mais especificamente, para Marcel, Schelling "preparou o terreno para ... um renascimento da metafísica em fundações não tradicionais", um renascimento extremamente necessário para satisfazer a um pensamento "cada vez mais cauteloso com a invasão de categorias legalistas, por um lado, e com a tentação dos hegelianos por outro." (MARCEL, 1957, p. 86)7.

Quando se trata de identificar os elementos da filosofia schellingiana que Marcel, Tillich e outros consideraram tão atraentes, geralmente são apresentados dois itens: sistema e liberdade (para utilizar a linguagem de Heidegger no curso de 1936 sobre a Freiheitsschrift). Como Marcel deixa claro no exposto, o neo-schellingianismo tem como premissa a rejeição de uma escolha entre o legalismo neokantiano e a metafísica hegeliana, entre a filosofia limitada ao sujeito e a especulação que o ignora ${ }^{8}$. Os neo-schellingianos eram precisamente aqueles

7 Ver mais em George Pattison, Anxious Angels: A Retrospective View of Religious Existentialism (Basingstoke: Palgrave Macmillan, 1999).

8 Ver mais em Gabriel Marcel, 'An Essay in Autobiography' in The Philosophy of Existentialism, trans. Manya Harari (New York: Citadel, 1956), 105-6. 
que queriam os dois. Também para Heidegger, "Schelling é o pensador verdadeiramente criativo e mais ousado de toda essa era da filosofia alemã" (1985, p. 4), precisamente porque ele pensa na compatibilidade do sistema (como "a tarefa de filosofia" (ibid, p. 27) e da liberdade (com sua própria "factualidade" peculiar (ibid, p. 164). Em geral, os neo-schellingianos são seguidores de Schelling na medida em que evitam a escolha exclusiva entre liberdade humana e metafísica. Eles escolhem os dois.

A segunda tese de doutorado de Tillich sobre Schelling (Misticismo e Culpa-Consciência no Desenvolvimento Filosófico de Schelling) está firmemente nessa tradição. O misticismo é "o sentimento de unidade com o absoluto" (TILLICH, 1974, p. 27). Apenas com base em alguma forma de afinidade entre o homem e Deus, afirma Tillich, qualquer conhecimento de Deus - e, portanto, uma teologia especulativa - pode ocorrer. Equiprimordial com esse princípio, no entanto, Tillich também postula a consciência de culpa, a "consciência de oposição a Deus ... a experiência de contradição entre o Senhor Santo e a criatura pecaminosa" " (ibid). Presente junto à união mística com Deus sempre está uma percepção de indignidade aos Seus olhos, e esse segundo elemento é o próprio princípio que a especulação filosófica suprime. Somente Schelling deu à consciência de culpa o status que merecia, segundo Tillich. Ao reconhecer a consciência de culpa e a identidade, Schelling permite um momento irracional em seu sistema. Como escreve Tillich, "o princípio supremo de toda a realidade [se torna] a identidade da essência e da contradição, do racional e do irracional (TILLICH, 1974, p. 112).

Ou seja, nenhuma teologia deve negar a separação entre o homem e Deus e a liberdade radical para pecar; no entanto, por outro lado, nenhuma teologia deve usar isso como desculpa para sacrificar a relação de Deus com o mundo e a especulação sistemática que isso possibilita. Ambos os aspectos (sistema e liberdade) devem ser mantidos, e a luta para conseguir isso é a luta do teologizar ${ }^{9}$. As conquistas de Schelling

9 Reivindicações semelhantes são feitas desde a tese de doutorado inicial de Tillich sobre Schelling. Diz-se aqui que Schelling combina dois métodos em seu filosofar sobre religião: um estudo antropológico do homem como doador de significado à religião e um exame metafísico das estruturas do ser que tornam a religião possível. Como tal, "para alcançar 
sempre permaneceram normativas para Tillich, fornecendo o modelo ao qual aspirar. A filosofia de Schelling exemplifica uma lógica 'tanto ... quanto...' a partir da qual resulta em um pensamento não dualista da liberdade humana incorporado e proporcional à realidade mais ampla.

No entanto, não é apenas a incorporação de sistema e liberdade em si que interessa a Tillich. Quando ele retorna a Schelling no final da década de 1940 e no início da década de 1950, começam a surgir as verdadeiras apostas do neo-schellingianismo tillichiano. Agora temos a insistência polêmica de Tillich de que Schelling foi "o antecessor de todos os existencialistas" (1967, p. 141), e que as últimas palestras de Schelling em Berlim representam "o documento original da filosofia existencial” (TILLICH, 1987, p. 394), mas também há algo mais: a correlação de sistema e liberdade é o que permite ao teólogo enfrentar a questão da preocupação última. Ou seja, como já vimos detalhadamente, Schelling 'tenta retornar a uma atitude na qual o abismo acentuado entre os reinos 'subjetivo' e 'objetivo' ainda não havia sido criado" (TILLICH, 1959, p. 107). E Tillich agora enfatiza: isso é feito em nome da revelação de uma condição transcendental subjetiva e objetiva da experiência. Schelling 'voltou-se para a 'subjetividade', não como algo oposto à 'objetividade', mas como a experiência de vida na qual a objetividade e a subjetividade estão enraizadas ... [Ele] tentou descobrir o domínio criativo do ser que é anterior e além da distinção entre objetividade e subjetividade" (TILLICH, 1959, p. 107). Esse domínio do ser é "a fonte de onde brota meu pensamento e minha ação” (TILLICH, 1959, p. 92). Localizar e descrever essa fonte é o próprio pináculo da crítica, pois essa é a condição transcendental que possibilita toda a vida.

a essência da religião, é necessário conceber a espiritualidade do homem em uma relação original e substancial com Deus. O método se torna especulativo". (The Construction of the History of Religion in Schelling's Positive Philosophy: Its Presuppositions and Principles, trans. Victor Nuovo (Lewisburg: Bucknell University Press, 1974, p.119) O ponto de partida antropológico no homem é combinado com uma extensão especulativa da filosofia para o homem em uma preocupação com Deus. Como Tillich expressou em 1948, "O caminho da ontologia passa pela doutrina do homem" (Paul Tillich, 'Existential Philosophy: Its Historical Meaning' in Theology of Culture, ed. Robert C. Kimball (New York: Oxford University Press, 1959), 98). 
A correlação entre homem e mundo (liberdade e sistema) é aqui reformulada como um meio de acessar outro princípio - piedade, o domínio primordial da preocupação última que orienta o ser como um todo e o sujeito humano em particular. A fonte transcendental da existência subjetiva e objetiva do ser é o fundamento/ abismo de toda a vida e é alcançada através de uma metodologia neo-schellingiana. Ou seja, Tillich (repetindo o idealismo alemão) identifica a tentativa kantiana de identificar as condições psicológicas da representação com a busca metafísica por razões de ser; isto é, ele percebe que "o estrato transcendental do conhecimento corresponde ao estrato transcendental do ser" (TILLICH, 1936, p. 158), e esse estrato transcendental crítico-especulativo é chamado de "preocupação última". Essa é, então, uma das funções centrais da correlação tilichiana em geral: a determinação da ultimacidade através de um discurso duplo do homem e do mundo.

A discussão da revelação no primeiro volume da Teologia Sistemática esclarece ainda mais esse nó de críticismo, correlação e ultimacidade. A revelação é definida precisamente como "a manifestação do que nos interessa, em última análise" (TILLICH, 1951, p. 110), a reorientação de foco para a piedade. Esse processo de reorientação consiste em dois momentos (que acabam entrando em colapso na identidade): um "lado negativo" da crítica e um momento positivo de especulação em que "abre uma nova dimensão do conhecimento, a dimensão do entendimento em relação à nossa preocupação última e ao mistério do ser." (TILLICH, 1951, p. 105). Este é, de fato, o momento crítico inicial que me preocupa aqui, um momento que é rigorosamente correlacionado por Tillich ao falar do "elemento abismal (objetivo) no fundamento do ser" (TILLICH, 1951, p. 110) e o choque extático da mente (elemento subjetivo).

A ameaça do não-ser, apreendendo a mente, produz o "choque ontológico" no qual é vivenciado o lado negativo do mistério do ser - seu elemento abismal. O termo 'choque' aponta para um estado de espírito em que a mente é arrancada de seu equilíbrio normal e abalada em sua estrutura. A razão atinge sua linha de fronteira, é lançada sobre si mesma e depois é novamente arrastada para sua situação extrema. (TILLICH, 1951, p. 113). 
A crítica - em sua forma tillichiana, schellingiana e Goodchildiana - leva a razão para além de si mesma ao seu fundamento e abismo, como "o início de toda filosofia genuína” (TILLICH, 1951, p. 113).

Portanto, limitar o neo-schellingianismo de Tillich ao inventário de liberdade e sistema é insuficiente; de fato, não atinge o que mais importa. Tal descrição inadequada tende a apontar Tillich como um metafísico que tenta fornecer uma descrição cosmológica da liberdade. O que argumento neste ensaio, no entanto, é que Tillich é um pensador crítico, e o que ele absorve de Schelling e transmite (indiretamente) para Goodchild é um projeto crítico, um discurso que nomeia e descreve as condições de nomear o que é importante, a preocupação última. Tillich é especulativo na medida em que é crítico e (em última análise) ele é crítico na medida em que é especulativo. Para Tillich e para os idealistas alemães, o projeto crítico pós-kantiano atinge um ponto indistinguível da especulação, "abolindo assim o contraste entre metafísica e epistemologia". ${ }^{10}$

Esta é (para recordar a epígrafe deste ensaio) uma repetição de críticas que transcendem as restrições impostas a ela nas tradições kantianas e neo-kantianas. Certamente, é possível encontrar muitos ataques a este último ao longo das obras de Tillich - desde o ataque ao neokantianismo que abre Misticismo e a consciência de culpa (TILLICH, 1974, p. 22) até o artigo de 1922 sobre Religionsphilosophie (publicado no Kantstudien Jahrgang) que aborda o vazio, o formalismo e o fideísmo do pensamento crítico (TILLICH, 1987, p. 125-130) até os comentários depreciativos que abarrotam a Teologia Sistemática (1951, p. 82-83). Grande parte da produção de Tillich deve ser definida de fato por "um protesto contra o formalismo metodológico dos kantianos" (TILLICH, 1936, p. 124). No entanto, defendo que o criticismo tout court não é descartado; ao contrário, retornam de uma forma mais originária como a descrição, transformação e melhoria do que nos interessa em última análise - ou, na linguagem da abertura da Teologia Sistemática, o teste e a interrogação dos conceitos teológicos por meio de critérios formais

10 Paul Tillich, citado em Gunther Wenz, 'An Introduction to Paul Tillich's Philosophical Writings' in Hauptwerke 1:12. Sobre esse ponto em relação a Goodchild, ver Joshua Ramey and Daniel Whistler, 'The Physics of Sense: Bruno, Schelling, Deleuze' in Edward Kazarian et al (eds), The Metaphysics of Gilles Deleuze (Lexington, MA: Lexington, 2013). 
para a ultimacidade ${ }^{11}$. A crítica retorna como a crítica da idolatria, e nesse caso, tal crítica não é extrínseca ao empreendimento teológico, mas a base a partir de onde ela perpetuamente recomeça ${ }^{12}$. Surge aqui, portanto, uma forma mutante de crítica que também é, conforme discutirei na próxima seção, a forma mais paradigmática de crítica ("crítica como tal") na medida em que identifica e descreve a condição transcendental de experiência subjetiva e objetiva de que Kant sente falta: preocupação última - ou piedade ${ }^{13}$.

\section{Crítica como tal}

A teologia se torna crítica no neo-schellingianismo de Tillich. Para enriquecer a descrição de tais críticas (e as condições de sua própria possibilidade), volto-me agora ao Capitalism and Religion de Philip Goodchild, que se alinha diretamente à tradição schelingiana e tillichiana, na medida em que concebe a tarefa do pensar como um encontro com e uma reorientação ao que mais importa. $\mathrm{O}$ capitalismo e a religião estão sob a mesma epígrafe marxista: "A crítica da religião é a premissa de toda crítica"14, que é um componente essencial da "transcendência" de Kant em Tillich. O desenvolvimento da tradição da teologia crítica no trabalho de Goodchild nos permite observar três aspectos principais: primeiro, o nó que existe entre crítica e crise (que é verificado em sua afinidade etimológica, mesmo que se estenda para além disso); segundo, a extensão da crise com a qual o pensador crítico deve se envolver; terceiro, a relação inextricável entre crítica e futuridade.

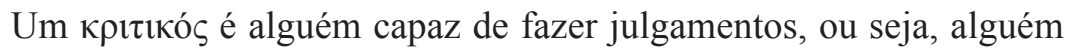

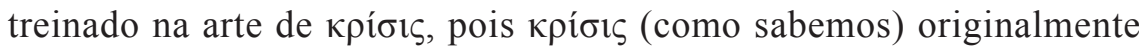
significava julgamento ou o ato de julgar. Um pensador crítico, consequentemente, também se preocupa com crises. Ele se preocupa não apenas em descrever as condições das crises já existentes, mas também

"Para esses critérios formais, consultar Tillich, Systematic Theology, 1: 12-4.

12 Conforme a discussão da noção tillichiana de "razão crítica" na conclusão desse ensaio.

13 Sobre a recusa de Kant em aceitar a piedade (e sua relação com o trabalho de Goodchild), ver Daniel Whistler, The Discipline of Pious Reason: Goethe, Herder, Kant' in Joseph Carlisle, James Carter and Daniel Whistler (eds), Moral Powers, Fragile Beliefs: Essays in Moral and Religious Philosophy (London: Continuum, 2011).

14 Karl Marx, A Contribution to the Critique of Hegel's Philosophy of Right citado em Philip Goodchild, Capitalism and Religion: The Price of Piety. London: Routledge, 2002, p. v. 
em discernir novas crises para o pensamento. Talvez isso possa sugerir uma brecha na auto-compreensão de Tillich do projeto crítico: pois, certamente, os primeiros trabalhos de Tillich geralmente assumem a forma de uma rejeição das teologias da crise (Barth, Gogarten) e, no entanto, a resposta de Tillich ao teólogo dialético é sempre radicalizar e intensificar a crise - "submeter-se não apenas dialeticamente, mas realmente ao paradoxo" (TILLICH, 1968, p. 141, grifos meus). O teólogo, portanto, deve se submeter completamente ao "Não" (ibid, p. 135) Nesse momento,

A teologia da crise está certa, completamente certa, em sua luta contra todo entendimento imparcial, imediato e objetivo dos incondicionados. Não é uma transição, mas algo permanente, um elemento na essência da teologia. Mas ela tem pressuposto que já não é mais uma crise (TILLICH, 1968, p.141).

Para Tillich, portanto, como para Goodchild e (como veremos) para Schelling, os крıєıкó pensam apenas em crises.

Enquanto o corpus kantiano responde à crise da metafísica e Tillich à crise da idolatria, o trabalho inicial de Goodchild responde da mesma forma à crise da piedade - uma crise que é simultaneamente ecológica, econômica e mental (GOODCHILD, 2002, p. 247). A natureza material dessas crises não deve ser negligenciada; o pensador crítico não é meramente provocado por ideias, mas pela falta (ou abundância) de matéria:

O último insight a chegar [ao escrever este livro] foi a verdade contemporânea do sofrimento: uma consciência crescente de que as tendências atuais da globalização, do comércio e da disseminação da tecnologia não estão apenas levando a uma condição em que o habitat humano é insustentável, mas a urgência e a responsabilidade anunciada pela catástrofe evitável significam que vale a pena pensar um pouco mais (GOODCHILD, 2002, p. xiii).

O projeto goodchildniano não pode, portanto, consistir apenas na identificação e descrição das condições dessas crises; precisa também melhorar, transformar e intensificar essas condições em nome de um futuro melhor, fundindo crítica e ativismo. Em outras palavras, Capitalism and Religion de Goodchild nada mais é do que uma investigação tríplice sobre a possibilidade de um futuro para o pensamento: um diagnóstico 
das condições atuais do pensamento assolado pela crise, uma descrição das condições futuras necessárias para renovar o pensamento e também crucialmente uma tentativa de atender a essas condições. Isso forma "uma teoria crítica da piedade" (GOODCHILD, 2002, p. 7).

Segundo Goodchild, a piedade designa o processo pelo qual selecionamos o que mais importa e mantemos um relacionamento com isso. A piedade é "uma prática determinada de direcionar a atenção para aquilo que importa” (GOODCHILD, p. 248). A piedade não é, de fato, a única condição do pensamento, mas, porque é o árbitro daquilo para o qual o pensamento é direcionado, é ao mesmo tempo necessária e universal. "Torna possível uma experiência significativa do mundo" (GOODCHILD, 2002, p. x). A piedade é uma condição transcendental do pensamento, correspondendo estruturalmente quase exatamente à ultimacidade tillichiana.

Novamente, podemos discernir que os pensadores dessa tradição crítica não apenas imitam o projeto crítico kantiano; eles são de fato mais críticos que Kant. E isso ocorre porque a crise da piedade (ou preocupação última) é a crise do pensamento por excelência. Goodchild, como Tillich e Schelling antes dele, situa o filósofo no local da crise como uma forma de crítica enquanto tal. Além disso, a crítica como tal não é apenas um pensamento de crise (como genitivo objetivo), mas o pensamento como crise (o genitivo subjetivo). Goodchild deixa isso particularmente claro no prefácio autobiográfico de Capitalism and Religion:

Cada uma dessas [crises] fraturou minha autoconsciência, expondo um abismo sob todos os meus pensamentos e relações comigo mesmo, com os outros e com o mundo. Tornei-me um estranho para as pessoas mais próximas a mim e a mim mesmo. Cada questão se impôs como uma força dinâmica no pensamento, um problema de importância ilimitada diante do qual mal me sinto preparado para começar a abordar ... [Por um lado] o consenso público está engajado em um vasto empreendimento de evasão, abrigando-se de maneira perversa e complacência letal. No entanto, cada um desses problemas chama e desperta outros. Qualquer pessoa que atenda com atenção ao significado desse problema pode arriscar ter seu mundo destruído. Pensar é quase tão perigoso quanto a complacência. (GOODCHILD, 2002, p. xiv). 
A crítica é um negócio perigoso, pois assume o risco de buscar, utilizar e reimplementar 'forças dinâmicas' liberadas pelo choque da catástrofe. $\mathrm{O}$ que geralmente nos protege desse perigo não é apenas a doxa do senso comum, mas também as "defesas e escudos da filosofia e da teologia contra o absoluto" (GOODCHILD, 2002, p. 13).

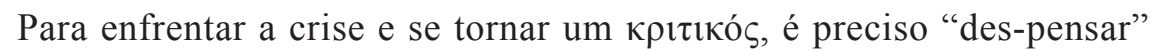
esses fundamentos.

Conforme Goodchild, esse impensado deve ser alcançado através de práticas de desorientação, como "a arte de cultivar estados extáticos" ou "uma experiência do intervalo caótico" (GOODCHILD, 2002, p. 194, 164). No limite, as potências do pensamento (definidas como "o incondicionado" dentro da experiência (ibid, p. 214) manifestam-se em uma "experiência apocalíptica" que finalmente disciplina a atenção ao que mais importa:

A consciência é normalmente fraca porque, embora possa direcionar a atenção, não há nada que possa revelá-la como foco de atenção. O impensável, embora seja pensado corretamente, normalmente não entra no pensamento. A piedade não pode optar por indicar uma potência. No entanto, a potência pode indicar a si mesma. Seja na catástrofe global ou na menor crueldade doméstica, o sofrimento é um sinal que indica um absoluto: há algo que importa, algo que nos motiva e nos empodera (GOODCHILD, 2002, p. 239-240).

Em uma crise, uma nova "ética do pensamento" libertadora (ibid, p. 250-251) pode se revelar; uma ética que atenda e reoriente nossa preocupação última. Aqui o pensamento enfrenta "o desafio da ética contemporânea ... encarnar esse excesso de força dentro da razão, para que a própria razão se torne uma força" (ibid, p. 157). E com esse ideal em mente, Goodchild conclui $\mathrm{Ca}$ pitalism and Religion nos seguintes termos tillich-schellingianos:

A consumação da piedade crítica surge na forma de consciência da potência, quando uma potência indica, dramatiza e se individualiza. Tal conscientização, uma experiência tão rara, capacita a atenção não mais para se concentrar apenas em si mesma, mas para dar atenção ao que está fora, àquilo que importa. Esse é o objetivo da filosofia. (GOODCHILD, 2002, p. 157). 
O ponto central da concepção de Goodchild do projeto crítico é a futuridade da piedade. Goodchild define piedade como "uma orientação para o futuro" (ibid, p. 177), transformando esse tipo de teoria crítica em um pensamento consciente de seu próprio futuro. Para entender o que está em jogo nessa concepção de crítica, é crucial reconhecer o papel das três "potências" de Goodchild e sua base nos rascunhos de Schelling, em Weltalter. Goodchild repete as três potências schellingianas da experiência como uma relação entre passado, presente e futuro. Ele fala de Weltalter como "uma dialética de potências [que] deve descrever a construção de modos de piedade e sua dissolução" (ibid, p. 229), concluindo: “Além da dialética impulsionada pela falta e pela contradição, Schelling indica que a vontade não apenas procure superar o passado, mas busque ativamente o futuro." (ibid, p. 112). À primeira vista, a leitura de Schelling feita por Goodchild parece derivada da leitura de Žižek. ${ }^{15}$ Como Zizek, Goodchild toma grande parte da página final do rascunho de 1813 da Weltalter: 'O Eterno leva a força da consciência mais elevada à inconsciência e a sacrifica à externalidade, para que haja vida e atualidade' (SCHELLING, 1997, p. 179). Esta passagem continua:

É assim que as coisas deveriam permanecer se houvesse um começo eterno, um fundamento eterno. Aquela ação primordial que torna o homem genuinamente ele mesmo precede todas as ações individuais; mas imediatamente após se posicionar em exuberante liberdade, esse ato afun-

15 A leitura de Zizek sobre Schelling concentra-se na noção de 'o Início' ou na auto-gênese de Deus: 'Como não há nada fora de Deus, ele deve gerar fora de si um Filho, isto é, a Palavra que resolverá a tensão insuportável. A pulsação indiferenciada dos impulsos é assim suplantada pela rede estável de diferenças, que sustenta a auto-identidade das entidades diferenciadas ... A consciência surge do ato primordial que separa a consciência atual e atual do domínio espectral e sombrio do inconsciente. (The Abyss of Freedom in F.W.J. Schelling, Ages of the World (Michigan: University of Michigan, 1997, p.23-33). Em termos lacanianos, essa é a "passagem do real para a história". (Ibid, 37) No entanto, decorre disso (de uma maneira lacaniana ortodoxa) que a realidade é formada às custas do Real (o passado): o início “é, em última análise, sempre inadequado, contingente. 'Trai' o sujeito, o representa inadequadamente" (The Indivisible Remainder: On Schelling and Related Matters (London: Verso, 2007,p. 43). O início sempre tem um preço: 'O preço é a perda irrecuperável da identidade própria do sujeito: o sinal verbal que representa o sujeito - no qual o sujeito se apresenta como auto-idêntico - carrega a marca de uma dissonância irredutível; nunca "se encaixa" no assunto. ' (Ibid, 47) A supressão do passado é "a lacuna intangível indescritível que sustenta a" realidade "”. (Ibidem, 68) 
da na noite da inconsciência. Este não é um ato que poderia acontecer uma vez e depois parar; é um ato permanente, um ato interminável e, conseqüentemente, nunca mais pode ser trazido à consciência ... Esse ato ocorre uma vez e depois afunda imediatamente de volta nas profundezas insondáveis (SCHELLING, 1997, p. 179).

Uma leitura apressada da interpretação de Goodchild poderia facilmente identificar piedade com a noção schellingiana de "começo". A piedade, como o passado, é inelutavelmente suprimida e esquecida no pensamento moderno ${ }^{16}$. A potência do passado, nessa leitura, é uma condição transcendental da existência que torna a vida possível, mas deve igualmente ser suprimida e empurrada para o passado para que isso ocorra. Um Goodchild zizekiano alegaria: tanto a postura quanto a negação da piedade são necessárias para a possibilidade de pensamento. Como o futuro do pensamento dependeria da supressão de todas as piedades, as críticas de qualquer forma se tornariam impossíveis.

O exposto acima já indica por que Goodchild não pode se inscrever nessa leitura Žižekiana do Weltalter e, de fato, ele se distancia explicitamente de Žižek (ibid, p. 174). Goodchild não identifica piedade com um passado necessariamente suprimido e indisponível; antes, Goodchild identifica piedade com a potência do futuro. Além disso, ele coloca esse futuro schellingiano da terceira potência em batalha com o futuro capitalista. Então, por um lado, há aquela visão morta e vazia do futuro que afirma:

Para economizar tempo é reinvestir o tempo que gastamos no próprio tempo. Esse processo intensificador reflexivo deixa pouco tempo de sobra para outras necessidades que exigem nossa atenção. A essência da ideologia contemporânea é uma atenção focada e fechada: ao focar nas expectativas sobre taxas de retorno futuras, extrapoladas de processos limitados no presente, e ao nos focar na economia de tempo, perdemos de vista a realidade (GOODCHILD, 2002, p. 74).

Por outro lado, há um futuro crítico que promete transformação, perguntando, nas palavras de Schelling: "O futuro não é apenas a ma-

16 Assim, Goodchild afirma: “A razão moderna elimina o acesso à piedade” (p. 6). Em outras palavras, "a piedade [é] invisível" porque a modernidade "surge de uma negação das práticas determinadas de direcionar a atenção". (Ibidem, 247-50). 
téria espiritual interior que ainda está oculta em todas as coisas deste mundo, apenas aguardando sua libertação?" (SCHELLING, 1997, p. 113). A questão principal, é claro, é como construir o último como resistência ao primeiro.

\section{Depois do dilúvio}

Goodchild, Tillich e Schelling afirmam (à sua maneira) a seguinte tese: o futuro nasce da catástrofe. A crise é um tema-chave no trabalho de Schelling a partir de 1809. A Freiheitsschrift, por exemplo, tem a intenção de mapear a erupção de bases (sejam geológicas, metafísicas, epistemológicas ou religiosas). A história da religião esboçada ao final deste trabalho segue o fundamento último e supremo (ou, no vocabulário de Tillich, a própria ultimacidade) à medida que se repete em formas mais ideais, transformando-se em luz, espírito e, finalmente, amor (SCHELLING, 1936, p. 56). No entanto, quando intercaladas são uma série de catástrofes. Por exemplo, “como o princípio das profundezas nunca pode dar origem a uma unidade verdadeira e completa, chega o momento em que toda essa glória decai como através de doenças horríveis e, finalmente, segue o caos" (ibid, p. 56), ou ainda,

Por fim, resulta a crise na turba gentium, que transborda as fundações do mundo antigo, uma vez que as águas do começo cobriram novamente as criações do tempo primitivo. (SCHELLING, 1936, p. 57-58).

A história na Freiheitsschrift incorpora uma inundação catastrófica, ou, nas palavras de Grant, "uma erupção geológica no meio da filosofia da liberdade" (GRANT, 2006, p. 17). Uma filosofia da piedade (uma filosofia do futuro) deve se preocupar com essas catástrofes, esses momentos quando a piedade como condição transcendental suprimida é finalmente revelada. Em termos prosaicos, o que mais importa para nós se torna particularmente claro em uma crise: essa é a afirmação comum que a ontologia geológica de Schelling tenta justificar.

Um mapeamento semelhante da alternância catastrófica de fundamento e não-fundamento domina a Historical-Critical Introduction to the Philosophy of Mythology. O tempo histórico e, portanto, a própria possibilidade do futuro, são construídos através da crise (um evento 
imprevisível de separação). Além disso, numa prefiguração da correlação tillichiana, Schelling articula essa crise nos discursos duplos de objetividade e subjetividade. Além da constituição de povos-nações separados por meio de crises (incluindo referências mais uma vez a um grande dilúvio primordial), esse evento também é "uma crise espiritual que... ocorreu na fundação da própria consciência humana" (SCHELLING, 2007, p. 73). Ela "abala a consciência em seu princípio, em sua fundação" como "um tremor da própria consciência" (palavras que novamente lembram a descrição da revelação de Tillich) (ibid, p. 75).

Assim, a condição necessária da possibilidade de um futuro para o sujeito e o mundo é uma crise. Fora da crise, o futuro emerge. Além do mais, para Schelling, a linguagem (particularmente a linguagem da mitologia, ou seja, os nomes divinos) é um registro privilegiado disso que surge no futuro através de uma catástrofe. É “um corpo de conhecimento humano imprevisível” (SCHELLING, 2007, p. 65) ${ }^{17}$. Daí compreende-se a afirmação crucial de Schelling: "Na formação das línguas mais antigas, uma riqueza de filosofia pode ser descoberta" (ibid, p. 75). Somente através do estudo da crise pela qual são reveladas questões de extrema preocupação o pensamento pode tornar-se adequado a si mesmo, intensificando o projeto crítico, como as últimas palavras do curso de palestras colocam.

De fato, é exatamente isso que Schelling se compromete a fazer em The Deities of Samothrace. O trabalho consiste em uma investigação dos cultos-de-mistério nativos gregos da ilha de Samotrácia e pergunta por que os deuses desse culto receberam os nomes que receberam e, para nossos propósitos, qual é a chave que Schelling estabelece entre uma catástrofe geológica e esses nomes divinos (nomear deuses, é claro, é um exemplo particularmente óbvio do processo de piedade ou manifestação de preocupação última ${ }^{18}$ ).

O trabalho começa com um levantamento geológico da ilha que se concentra em particular em uma inundação pré-histórica (mais uma vez):

17 Os poemas homéricos, em particular, são documentos desse processo: 'A crise ... ocorre nos próprios poetas, forma seus poemas'. Ibid, 18.

18 Portanto, a definição de Tillich de "deuses" na Teologia sistemática: "Deuses ... são expressões da preocupação última que transcende a divisão entre subjetividade e objetividade". (1:214) 
Os geógrafos antigos supunham que grandes convulsões da natureza afligiam essas regiões até os tempos humanos. Pode ser que as águas do mar Negro, erguidas simplesmente pelas enchentes, tenham rompido primeiro o estreito da Trácia e, depois, o Hellespont. Ou que a força de um vulcão subterrâneo alterou o nível das águas. As histórias mais antigas de Samotrácia, transmutadas em monumentos exibidos em comemoração, preservaram um relato desse evento e, a partir de então, promoveram a reverência e o patrocínio dos deuses nativos (SCHELLING, 1977, p. 15). ${ }^{19}$

Uma erupção de bases geológicas deu origem a uma catástrofe (comemorada nas 'histórias mais antigas de Samotrácia') que, por sua vez, provocou uma nova reverência pelo divino entre o povo de Samotrácia. Schelling insiste que os cultos-de-mistério dos samotracianos nascem de uma "grande convulsão da natureza" (a "turba gentium" da Freiheitsschrift). As apostas críticas dessa passagem da abertura devem agora ser esclarecidas: somente em crises o pensador pode obter acesso aos fundamentos; só então ele pode "pensar teologicamente". Momentos de catástrofe - como as inundações de Samotrácia - tornam possível um pensamento crítico tentando identificar suas próprias condições. A crítica deve tomar toda e qualquer crise como objeto, incluindo as inundações de Samotrácia - e isso é especialmente verdadeiro quando tal catástrofe já foi comemorada e atestada na religião das pessoas afetadas por ela. Os fundadores dos cultos-de-mistério samotracianos foram крıєıкó por excelência, pois, situados no local de uma crise, inventaram novas formas de discurso e (mais significativamente) novas piedades para testemunhar o fundamento que lhes foi manifestado. Esse é um arquétipo da crítica como tal e talvez seja por essa razão que Schelling dedique um tratado a ele. A análise de Schelling dos cultos-de-mistério samotracianos é um meio de localizar as piedades que emergiram durante a crise. $\mathrm{O}$ pensamento só tem futuro se essas piedades puderem ser descritas e essa descrição depende de pensar (como) catástrofe (como Schelling faz aqui). Analisar filosoficamente os nomes divinos é revelar simultaneamente o funcionamento do pró-

19 F.W.J. Schelling, The Deities of Samothrace, ed. and trans. Robert F. Brown (Missoula: Scholars Press, 1977), 15. For more on this reading of Deities, see Daniel Whistler, 'Language after Philosophy of Nature: Schelling's Geology of Divine Names' in Anthony Paul Smith and Daniel Whistler (eds), After the Postsecular and the Postmodern: New Essays in Continental Philosophy of Religion (Newcastle: CSP, 2010). 
prio criticismo: The Deities of Samothrace são, em última análise, um empreendimento meta-filosófico.

\section{O direito de nomear, ou voltar a Kant}

$\mathrm{O}$ que foi acima exposto pode parecer ter se desviado muito de Tillich; no entanto, uma análise de duas citações pode mostrar rapidamente o contrário. Primeiro:

Podemos falar daquilo que é mais vital no presente, daquilo que faz do presente uma força geradora, apenas na medida em que alguém se imerge no processo criativo que traz o futuro para fora do passado (TILLICH, 1956, p. 34).

"O que é mais vital no presente" ou o que nos preocupa, em última análise, é constituído e atendido através de uma síntese do tempo - de acordo com a afirmação de Goodchild, "modos de piedade são sínteses do tempo" (GOODCHILD, 2002, p. 191). Eventos passados trazem o futuro, e é apenas um pensamento que se submete a esse processo temporal (em paralelo, se não estiver em identidade com sua submissão à crise), que pode genuinamente ser chamado de crítico. De fato, Tillich até interpreta Schelling (e particularmente seu Weltalter) através dessa mesma idéia de "história vista à luz do futuro" (TILLICH, 1959, p. 101).

O Schelling de Tillich é o mesmo Schelling goodchildiano da terceira potência, assim como o projeto crítico de Tillich como um todo caracteriza-se por estar atento ao futuro do pensamento.

A segunda citação é retirada da tipologia da razão de Tillich, na abertura de Perspectives. Aqui ele afirma sem muito entusiasmo o poder revolucionário da "razão crítica":

Não era uma razão calculadora que decidisse fazer isso ou aquilo, dependendo de qual fosse mais vantajoso. Antes, era uma ênfase completa, apaixonada e revolucionária na bondade essencial do homem em nome do princípio da justiça (TILLICH, 1967, p, 32).

Tillich passa a rotulá-la de "razão revolucionária", e, ao fazê-lo, vincula a crítica inextricavelmente ao poder de mudar o futuro, reorientar as preocupações últimas e administrar as piedades de maneira diferente. Em suas invocações de justiça e revolução, ele também expli- 
cita um tema que borbulha sob a superfície deste ensaio desde o início: crítica e política. E é com esse link que quero concluir.

O que está em jogo aqui é o direito ou a legitimidade pela qual

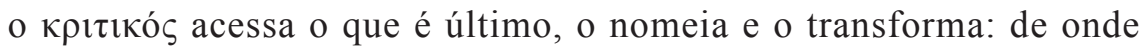

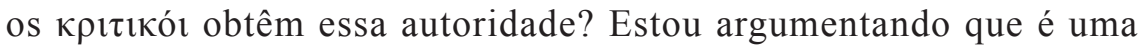

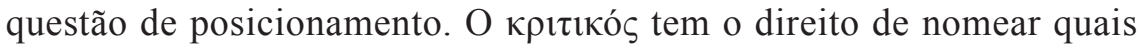
fundamentos e não fundamentos experimenta, porque fica na posição em que o fundamento é mais acessível. Trata-se, portanto, da proximidade com a qual se confronta a crise - isto é, da política.

As críticas, como tais, conforme argumentei, preocupam-se com as crises. Situam-se em experiências limitadas onde a piedade (ou o futuro) se manifesta. O que orienta o pensamento e a ação somente fica claro em uma crise - e, como esse princípio de orientação é uma chave de condição transcendental, a crítica não é crítica como tal, a menos que pense (em) crise. O крıєıкó deve procurar as crises na turba gentium, porque é lá que o futuro é fabricado. Há um perigo aqui e é um perigo de que Kant, em particular, tinha plena consciência - o perigo da proximidade. Um revolucionário, Kant sugere, não é um pensador crítico, porque a crítica exige distanciamento do que está sendo descrito. Essa crítica que se coloca muito perto da catástrofe não pode mais ser crítica. É esse perigo que Kant chama de "fanatismo"20. Existem duas razões relacionadas pelas quais um fanático revolucionário não pode ser um

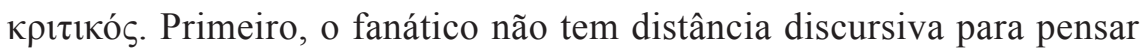
sobre a crise. No meio da própria crise, não há posição privilegiada para descrever seu conteúdo e ver o fundamento como ele se revela. O fanático está muito perto. Segundo, escreve Kant, o fanatismo "é a ilusão de querer ver algo além de todos os limites da sensibilidade" (KANT, 1987, p. 276). Para nossos propósitos, esse é o erro da impaciência: em vez de esperar o surgimento do futuro na crise, o fanático tenta percebê-lo muito rapidamente, para se antecipar a ele. O крıєı́́s

20 As duas principais discussões sobre fanatismo - fora da passagem da Crítica do Juizo citada abaixo - ocorrem no Essay on the Maladies of the Head, 2: 267 e Observations on the Feeling of the Beautiful and the Sublime, 2: 251 (ambos coletados em Immanuel Kant, Observations on the Feeling of the Beautiful and the Sublime, trad. E ed. Patrick Frierson e Paul Guyer (Cambridge: Cambridge University Press, 2011). Minha discussão sobre Kant nos próximos dois parágrafos depende de Alberto Toscano, Fanaticism: On the Uses of an Idea (London: Verso, 2010), 120-46. (London: Verso, 2010), p. 120-46. 
deve ser paciente. É isso que Goodchild designa como "fé absoluta": "A fé absoluta permite que o futuro seja constituído como um presente das potências. A fé absoluta espera". (GOODCHILD, 2002, p. 237).

Isso representa um problema. Ao longo deste ensaio, argumentei que Kant não foi longe o suficiente; ele não praticou o criticismo como tal. Sua exclusão do fanático é outro exemplo desse fracasso em cultivar a crítica como tal ou deve seguir esse pensamento crítico ao proibir a figura do fanático do pensamento crítico? De fato, essa pergunta não precisa ser respondida de frente, pois o próprio Kant oferece uma saída para essa dicotomia severa por meio de um conceito adicional - entusiasmo. Entusiasmo é um meio de participar de uma revolução $e$ ser crítico. O entusiasmo para Kant "é um esforço de nossas forças por ideias que transmitem à mente um momento cujos efeitos são mais poderosos e permanentes do que os de um impulso produzido por apresentações de sentido" (KANT, 1987, p. 272) 21. É “o estado de espírito em que se tornou inflamado por qualquer princípio acima do nível adequado" (KANT, 2011, p. 251). Ou seja, o entusiasmo é um excesso de atenção, um estado no qual a preocupação última se torna mais manifesta. Portanto, para Kant, "nada de bom no mundo foi feito sem [entusiasmo]" (KANT in TOSCANO, 2010, p. 123) A história (o futuro) só acontece pelo entusiasmo (atenção ao que é último) - um padrão que foi repetido ao longo deste ensaio.

Toscano recentemente chamou a atenção para o papel construtivo do entusiasmo na filosofia política de Kant. Argumentando contra Arendt, Lyotard, Critchley e todos aqueles que vêem Kant como um filósofo da neutralidade, um anti-entusiasta, Toscano desenvolve a ideia do filósofo como espectador partidário a partir dos escritos de Kant sobre a Revolução Francesa. Kant não aconselha o filósofo (ou qualquer cidadão esclarecido) a permanecer apático e indiferente aos acontecimentos na França; em vez disso, ele recomenda que qualquer espectador a respeito desses eventos de longe sinta entusiasmo com o que vêem - e esse entusiasmo revela 'uma tendência e uma faculdade da natureza humana para melhorar" (KANT, 1996, p. 304). Toscano continua:

21 Kant nem sempre usa 'entusiasmo' tão positivamente, veja, por exemplo Observations, 2:221. 
O que permite que a participação afetiva desses espectadores no bem sirva como sinal do progresso humano não é sua imparcialidade, mas o próprio fato de que, sob o risco de perseguição, estão tomando partido pela revolução. Não é a imparcialidade, mas o partidarismo que define a importância universal do julgamento político ... Esses não são espectadores objetivos e desencarnados, julgando em termos de uma visão desapaixonada do todo; eles incorporam um partidarismo apaixonado, porém desinteressado... o espectador 'age' por meio da escolha arriscada do partidarismo público, e que o que seu entusiasmo indica é a própria capacidade do ser humano de ser um agente político histórico coletivo (TOSCANO, 2010, P. 143-144).

O pensador crítico é um partidário entusiasmado. Embora ele não seja um militante fanático situado na briga (tão sujeita aos erros do imediatismo e da impaciência), também não é apático e despreocupado. Ele possui distância discursiva, mas ainda responde à crise. Além disso, e aqui Kant é insistente, algo mais é revelado a esse filósofo entusiasmado: o entusiasmo revela a faculdade humana de melhoria. A

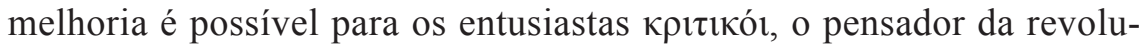
ção ou a catástrofe. Nesse ponto, Kant aproxima-se muito de Tillich, Schelling e Goodchild.

Como coda a essa invocação da política de crítica ou uma extensão de seu alcance cultural, um trabalho final citado por Toscano deve ser trazido para enriquecer a problemática: Os sertões de Euclides da Cunha. ${ }^{22} \mathrm{O}$ que é notável no livro de da Cunha é que ele toma como objeto todas as crises abordadas neste ensaio (e mais) em nome da compreensão da formação e orientação de uma futura comunidade política. É a síntese de todas as tentativas de crítica enquanto tais. Os Sertões começa com um extenso levantamento geológico da região muito relevante do Brasil, à maneira das Deities of Samothrace de Schelling. Como Toscano aponta, "a violência geológica parece pressagiar e preparar a política apocalíptica" (p. 62). As crises geológicas também são crises da política e da religião: em todas as três, as mesmas piedades, as mesmas preocupações, o mesmo futuro, são reveladas. Além disso, da Cunha invoca explicitamente esses vínculos entre política, religião e geologia em nome da profecia - isto é, em nome do futuro. Os sertões

22 Utilizo a seguinte tradução: CUNHA, Euclides, Rebellion in the Backlands, trans. Samuel Putnam (Chicago: University of Chicago Press, 1985.) 
se propõe à tarefa de usar essas crises, revoluções e catástrofes como meio de descobrir o futuro para o povo do Brasil. O futuro do Brasil é fabricado a partir desses eventos passados, porque nesses eventos as preocupações últimas da sociedade brasileira são reveladas. Assim como Schelling nas Deities of Samothrace, da Cunha se une à geologia e ao milenarismo, e esse carnaval eclético de gêneros, assuntos e conceitos reorganizados em nome de revelar o que realmente importa, em minha opinião, é semelhante ao projeto de Tillich e, portanto, pode ser chamada de "filosofia crítica como tal".

\section{Referências Bibliográficas}

Altizer, Thomas J. J. The Call to Radical Theology. Edited by Lissa McCullough. Albany: SUNY, 2012.

DA CUNHA. Euclides. Rebellion in the Backlands. Translated by Samuel Putnam. Chicago: University of Chicago Press, 1985.

DANZ, Christian. Religion als Freiheitsbewußtsein. Berlin: De Gruyter, 2000.

DESCARTES, René. The Principles of Philosophy. In Meditations and Other Metaphysical Writings, translated by Desmond M. Clarke. London: Penguin, 1998.

GOODCHILD, Philip. Capitalism and Religion: The Price of Piety. London: Routledge, 2002.

GRANT, Iain Hamilton. Philosophies of Nature after Schelling. London: Continuum, 2006.

HEIDEGGER, Martin. Schelling's Treatise on the Essence of Human Freedom. Translated by Joan Stambaugh. Athens OH: Ohio University Press, 1985.

JASPERS, Karl. Schelling: Größe und Verhängnis. Munich: Piper, 1955.

JOHNSON, Bradley A. Making All Things New: Kant and Rancière on the Unintentional Intentional Practice of Aesthetics. In Anthony Paul Smith and Daniel Whistler (eds), After the Postsecular and the Postmodern: New Essays in Continental Philosophy of Religion. Newcastle: CSP, 2010.

. The Characteristic Theology of Herman Melville: Aesthetics, Politics, Duplicity. Eugene, OR: Pickwick, 2012.

KANT, Immanuel. Critique of Pure Reason. Translated by Norman Kemp Smith. Basingstoke: Palgrave Macmillan, 1929.

Critique of Judgment. Translated by Werner Pluhar. Indianapolis: Hackett, 1987. 
. The Conflict of the Faculties. In Religion and Rational Theology, translated and edited by A.W. Wood and George di Giovanni. Cambridge: Cambridge University Press, 1996, p. 233-328.

. Observations on the Feeling of the Beautiful and the Sublime, translated and edited by Patrick Frierson and Paul Guyer. Cambridge: Cambridge University Press, 2011, p. 11- 64.

Essay on the Maladies of the Head. In Observations on the Feeling of the Beautiful and the Sublime, translated and edited by Patrick Frierson and Paul Guyer. Cambridge: Cambridge University Press, 2011, p. 205-20.

KELLER, Catherine. Face of the Deep: A Theology of Becoming. London: Routledge, 2003.

LACOUE-LABARTHE, Philippe and NANCY, Jean-Luc. The Literary Absolute: The Theory of Literature in German Romanticism. Translated by Philip Bernard and Cheryl Lester. Albany: SUNY Press, 1988.

MARCEL, Gabriel. An Essay in Autobiography. In The Philosophy of Existentialism, translated by Manya Harari. New York: Citadel, 1956, p. 104-28. 'Schelling fut-il un précurseur de la philosophie de l'existence?'

Revue de Metaphysique et de Morale (1957): p.72-87.

MARX, Karl. A Contribution to the Critique of Hegel's Philosophy of Right. http://www.marxists.org/archive/marx/works/1843/critique-hpr/intro. htm; last accessed: 17/03/13.

NORMAN, Judith and WELCHMAN, Alistair. Editors' Introduction to The New Schelling. London: Continuum, 2004, p. 1-16.

PATTISON, George. Anxious Angels: A Retrospective View of Religious Existentialism. Basingstoke: Palgrave Macmillan, 1999.

RAMEY, Joshua and WHISTLER, Daniel. The Physics of Sense: Bruno, Schelling, Deleuze. In Edward Kazarian et al (eds), The Metaphysics of Gilles Deleuze. Lexington, MA: Lexington, 2013, p. 87-109.

SCHELLING, F.W.J. Inquiries into the Essence of Human Freedom. Translated by James Gutmann. La Salle: Open Court, 1936.

The Deities of Samothrace. Edited and translated by Robert F. Brown. Missoula: Scholars Press, 1977.

Ages of the World. Translated by Judith Norman. Michigan: University of Michigan Press, 1997, p. 105-82.

. Historical-Critical Introduction to the Philosophy of Mythology. Translated by Mason Richey and Markus Zisselberger. Albany: SUNY, 2007. 
TILLICH, Paul. The Interpretation of History. Translated by Elsa L. Talmey. New York: Scribner, 1936. Chicago Press, 1951.

. Systematic Theology. 3 volumes. Chicago: University of . The Courage to Be. London: Fontana, 1952.

. The Religious Situation. Translated by H. Richard Niebuhr. Cleveland: Meridian Books, 1956.

. Existential Philosophy: Its Historical Meaning. In Theology of Culture, edited by Robert C. Kimball. New York: Oxford University Press, 1959, p. 76-111.

. Perspectives on Nineteenth and Twentieth-Century Protestant Theology. Edited by Carl E. Braaten. London: SCM, 1967.

. Critical and Positive Paradox. Translated by Keith R. Crim. In James M. Robinson (ed), The Beginnings of Dialectical Theology. Richmond: John Knox, 1968, p. 133-62.

. On the Boundary. Translated by J. Heywood Thomas. In The Boundaries of Our Being. London: Fontana, 1973, p. 285-350.

. The Construction of the History of Religion in Schelling's Positive Philosophy: Its Presuppositions and Principles. Translated by Victor Nuovo. Lewisburg: Bucknell University Press, 1974.

. Mysticism and Guilt-Consciousness in Schelling's Philosophical Development. Translated by Victor Nuovo. Lewisburg: Bucknell University Press, 1974.

. Schelling und die Anfänge des Existentialistischen Protestes. In Hauptwerke, edited by John Clayton et al. Volume 1. Berlin: De Gruyter, 1987, p. 392-401.

. Religionsphilosophie. In Hauptwerke, edited by John Clayton et al. Volume 4. Berlin: De Gruyter, 1987, p. 117-70.

. Philosophy and Theology. In Hauptwerke, edited by John Clayton et al. Volume 4. Berlin: De Gruyter, 1987, p. 279-88.

TOSCANO, Alberto. Fanaticism: On the Uses of an Idea. London: Verso, 2010.

WHISTLER, Daniel. Language after Philosophy of Nature: Schelling's Geology of Divine Names. In SMITH, Anthony Paul and WHISTLER, Daniel (eds), After the Postsecular and the Postmodern: New Essays in Continental Philosophy of Religion. Newcastle: CSP, 2010. 335-59. 
.. The Discipline of Pious Reason: Goethe, Herder, Kant. In CARLISLE, Joseph, CARTER, James and WHISTLER, Daniel (eds), Moral Powers, Fragile Beliefs: Essays in Moral and Religious Philosophy. London: Continuum, 2011. 53-81.

WENS, Günther. An Introduction to Paul Tillich's Philosophical Writings. In Hauptwerke, edited by John Clayton et al. Volume 1. Berlin: De Gruyter, 1987, p. 11-20.

ŽIŽEK, Slavoj. The Indivisible Remainder: On Schelling and Related Matters. London: Verso, 2007.

. The Abyss of Freedom. In F.W.J. Schelling, Ages of the World. Michigan: University of Michigan Press, 1997, p. 1-104. 